\title{
Evaluation of factors associated with noncompliance in users of combined hormonal contraceptive methods: a cross-sectional study: results from the MIA study
}

\author{
Txantón Martínez-Astorquiza-Ortiz de Zarate*, Teresa Díaz-Martín, Txantón Martínez-Astorquiza-Corral
} on behalf of the MIA Study Investigators

\begin{abstract}
Background: Understanding contraception from the perspective of the user may help to improve compliance. The aim of this project was to determine the factors that influence the noncompliance in young women that use combined hormonal contraceptives (pill, patch or vaginal ring).

Methods: A nationwide cross-sectional multicenter epidemiology study. Physicians [obstetricians/gynecologists]) recorded socio-demographic, clinical and current contraception data of 8,762 women. Women completed a selfadministered questionnaire on compliance. After the assessment of self-administrated questionnaire, the physicians reported on their recommendations on the possibility of changing the contraceptive.

Results: Fifty-two percent of women were noncompliant, mainly because of simple forgetfulness (pill, 74.9\%; patch, 47.8\%; vaginal ring, 69.1\%). The percentage of noncompliant women was lower in vaginal ring users (26.6\%) than in patch users $(42.4 \%)$ or pill users $(65.1 \%)(p<0.0001)$. The most common course of action after noncompliance was to take/use the contraceptive as soon as possible. In the multiple logistic regression analysis, the use of the pill increased the probability of noncompliance compared with the patch and the vaginal ring (odds ratio [IC95\%]: 2.53 (2.13-3.02) and 4.17 (3.68-4.73, respectively), and using the patch compared with the vaginal ring (1.65 (1.36-1.99)). Others factors associated with noncompliance were: high treatment duration, low degree of information on the contraceptive method, understanding of instructions on the contraceptive method, indifference to becoming pregnant, lack of partner support, not participation in selecting the method, not having a routine for taking treatment and difficulties remembering use the contraceptive method. Switching contraceptive method was proposed by the physicians to $43.2 \%$ of women $(51.8 \%$ of pill users, $58.2 \%$ of patch users and $19.4 \%$ of vaginal ring users).

Conclusions: More than $50 \%$ of combined hormonal contraceptive users did not comply with the treatment regimen. The percentage of noncompliant women was lower between vaginal ring users. Understanding user's reasons for noncompliance by the clinician and encouraging a collaborative approach can go a long way to improving compliance.
\end{abstract}

Keywords: Compliance, Combined oral contraceptive, Transdermal (contraceptive) patch, Vaginal (contraceptive) ring, Switching

\footnotetext{
*Correspondence: txantonma@gmail.com

Department of Gynecology, Hospital de Cruces, 48903 Barakaldo, Spain
} 


\section{Background}

4.7 million European women aged 15-49 are estimated to be at risk of an unintended pregnancy [1]. A national survey in Spain showed that, although $69.1 \%$ of women of childbearing age used some type of contraception [2], the efficacy of the method was poor in $5 \%$ of the cases. In addition, $30.9 \%$ of women did not use any method, leaving more than 1 million women at risk of unintended pregnancy. The consequences of noncompliance are far reaching. According to Darney [3], almost half of the 6.3 million pregnancies in the US are unintended, despite the availability of a wide variety of highly effective contraceptive methods.

Combined oral hormonal contraceptives are a safe and efficacious method of protection against unintended pregnancy. However, they are not always used consistently [4], and as many as $47 \%$ of women using combined oral contraceptives in the United States miss at least 1 pill per cycle [5]. A European study showed that 19\% of women aged 16 to 30 years missed 1 or more pills per cycle and those women were 2.6 times more likely to have an unintended pregnancy than the ones who miss less than 1 pill per cycle [6]. The efficacy of oral contraception depends on continued intake [6]. In many cases, poor compliance can be attributed to human factors [7], such as lack of a fixed routine for pill taking, misinterpretation of the information in the package insert, scant advice from health care providers, and side effects (eg, bleeding irregularities, nausea, and breast tenderness) [6]. Incorrect pill taking can lead to discontinuation and unintended pregnancy $[4,8]$.

Therefore, methods that reduce the frequency of dosing could increase compliance [8]. Alternative delivery methods for combined hormonal contraceptives have been developed over the years; such as the transdermal patch and the vaginal ring [9]. Matters of convenience seem to be especially important for women when selecting the patch or ring. Both offer advantages over the pill; for example, they can be used weekly or monthly, are easy of use and have lower likelihood of forgetting it [10].

Women's perceptions influence their contraceptive decisions. Indeed, poor compliance generates a significant care burden in terms of user's anxiety about preventing pregnancy and an increase of visits to the gynecologist for advice [11]. To support informed contraceptive decision-making, healthcare professionals should realize that the perception women have on the method's ease of use is more important than perceived efficacy, tolerability, health benefits or risks [10].

Acceptance of the vaginal ring has been shown to be higher (46\%) than for the pill (39\%) and skin patch (15\%), mainly because of the lower probability of inadvertent omission [12]. In addition, the efficacy and tolerability profile of the vaginal ring is comparable to that of combined oral contraceptives [13], and women are more likely to continue using it than women who take a combined oral contraceptive [14]. Other authors report the degree of satisfaction with the transdermal patch to be higher than with other delivery methods [15].

Studying the reasons for noncompliance enables us to understand contraception from the point of view of the user, and some authors have assessed the self-reported impact of noncompliance, which may have a negative impact in the user's behavior in front of working activities and/or with their couple [11].

The primary objective of the study was to determine what factors are associated with noncompliance in two types of user: 1) young women (18-28 years) or 2) women with little experience of combined hormonal contraceptives (maximum 2 years before the visit), in the case of women over 28 years.

The analyzed data about the advice given to users by the gynecologists and the level of acceptance of this advice should place clinicians in a better position to help women select the most suitable method for them or to recommend a more effective method when necessary.

The study describes the profile of the noncompliant user and presents the advice given by the gynecologist depending on the degree of noncompliance, user profile and reasons for noncompliance.

\section{Methods}

In order to analyze compliance with contraceptive use a nationwide cross-sectional multicenter study was performed. Subjects were recruited both in centers of the Spanish National Health Service and in private health centers. Since the primary endpoint of the study was to describe the factors associated with noncompliance and these would only be described by the noncompliant user; the size of the sample must be estimated taking into account the market share in Spain of the various contraceptive methods and the estimated percentage of noncompliant users for each of them (REMO Study: $71 \%$ pill, $32 \%$ patch and $21.6 \%$ vaginal ring) [11]. Based on the estimated market share in Spain of various studies of contraceptive methods (pill 74\%, patch 7\%, vaginal ring 19\%) and an assumption of an overlap of $80 \%$ between the 2 types of user (young women and women with little experience of their contraceptive method) a total of 12,000 users was calculated to be necessary to guarantee a minimum sample of 380 per group (pill, patch or vaginal ring) with a margin of error of $5 \%$ and a maximum uncertainty in noncompliance $(\mathrm{p}=\mathrm{q}=0.5)$, even in the least used method (patch).

In order for women being included in the study they had to be currently using a combined hormonal contraceptive (pill, patch or vaginal ring). In addition, women had to meet at least one of the following inclusion criteria: 1) had to be 
aged 18 to 28 years or 2) have little experience of their chosen contraceptive method (maximum 2 years before the visit). Women participating in a clinical trial or who were not capable of completing the questionnaire (investigator criteria) were excluded.

Data were collected from the clinical history at a single routine visit to the gynecologist [see Additional file 1]. The physician recorded sociodemographic data (age, educational level, occupational status, stable partner), obstetric history (number of births, abortions [spontaneous and induced], number of live childbirths), and data on the current contraceptive method. A self-administered questionnaire on contraceptive compliance was completed by the woman during the visit. The type of questionnaire varied according to whether they used pill, patch, or vaginal ring. A lack of strict compliance was evaluated by means of questions on forgetting to take the contraceptive, taking the contraceptive late, discontinuing the contraceptive, and incorrect use of the contraceptive. In cases of noncompliance, the woman was asked about the reasons and circumstances that led to noncompliance.

A compliant user was defined as a woman who always used her contraceptive method without no delays or omissions, according to the question in the selfadministered questionnaire "Have you delayed/forgotten sometime in the use of your contraceptive method? (Yes/No)". A noncompliant user was defined as one who missed or delayed using her contraceptive method at least once since the last visit. Delay was defined according to the Summary of Product Characteristics of each method.

Finally, after assessing the self-administered questionnaire, taking into account the user's profile, the degree of noncompliance and its reasons, the gynecologist recorded his/her recommendation at the visit, as was the woman's acceptance or rejection of the recommendation and the current type of contraception and the type that was recommended. If a change of method was recommended, the reason for this recommendation was indicated too.

The Ethics Committee of Hospital Clínic (Barcelona, Spain) approved the study according to the legislation in force at the time (Spanish Ministerial Order SAS/3470/ 2009), and all the patients gave their written informed consent to participate.

The characteristics of the women were described using a frequency table for categorical variables and measures of central tendency and dispersion for continuous variables. A bivariate analysis was performed to describe women's profile in terms of the contraceptive method used. Contingency tables (of categorical variables) were analyzed using the chi-squared test or Fisher exact test. Continuous variables were analyzed using a $t$ test or an analysis of variance, as long as the normality assumption was satisfied; non-normally distributed variables were analyzed using a nonparametric method (WilcoxonMann-Whitney or Kruskal-Wallis) for independent samples. A multiple logistic regression analysis (stepwise method) was performed to determine the factors that affect whether a woman is compliant or not. Statistical significance was set at a 2 -sided $\mathrm{p}$-value of $<.05$. The statistical analysis was performed using SAS v.9.2 (SAS Institute Inc., Cary, North Carolina, USA).

\section{Results}

The gynecologists collected data of 9,367 women, from which 8.762 (93.5\%) met inclusion criteria (1. young women [18-28 years] or 2 . women over 28 years with little experience of combined hormonal contraceptives (maximum 2 years before the visit)).

Mean (SD) age was 25.3 (4.8) years and most of the women were nulligravid. In addition, $57.3 \%$ worked outside the home and $27.2 \%$ were students (Table 1 ). The most commonly used contraceptive method was the pill (61.9\%), followed by the vaginal ring (28.4\%) and the patch $(9.8 \%)$. The pill had also been used for a longer period of time than the other methods (mean 30.8 months vs 19.3 and 21.6 months for the patch and vaginal ring, respectively $[\mathrm{p}<0.0001]$ ).

According to the definitions in the Material and methods section, $52.0 \%$ of women were noncompliant, with significant differences depending on the type of contraception used $(\mathrm{p}<0.0001)$ (Figure 1).

The most common reasons for omission/delay of using a contraceptive method were simple forgetfulness (Table 1), with differences observed between contraceptive methods $(p<0.0001)$. Specific reasons of each contraceptive method included the desire to hasten the occurrence of /postpone withdrawal bleeding (13.6\%) and accidental expulsion (6.9\%) in women using the vaginal ring. In the case of the patch, the reasons included accidental detachment without the user realizing (29.4\%), acne and discomfort when sand got below the patch. In pill users, the reasons included not being in the right place, hastening the occurrence of withdrawal bleeding and rest period.

Most women had a routine to remind them to take/ use their contraceptive method, observing statistically significant differences between the contraceptive method used ( $\mathrm{p}<0.0001)$. Remembering to use the contraceptive method was more difficult on vacation (31.3\%), especially in vaginal ring users $(\mathrm{p}<0.0001)$, during the weekend $(27.7 \%)$ and after going out the previous night $(12.9 \%)$, especially in pill users $(\mathrm{p}<0.0001)$. Women also found it difficult to use their contraceptive during trips to different time zone areas $(\mathrm{p}<0.0001)$ (Table 1$)$.

The most common course of action after noncompliance was to use the contraceptive as soon as possible. Women also consulted a health care provider, especially 
Table 1 Profile of the study population according to delivery system

\begin{tabular}{|c|c|c|c|c|c|}
\hline & Total & Pill & Patch & Ring & p Value \\
\hline Age, years (mean (SD)) & $25.29(4.79)$ & $25.14(4.81)$ & $25.49(4.78)$ & $25.56(4.71)$ & $<0.0001^{a}$ \\
\hline Time using the current method, months (mean (SD)) & $27.08(24.84)$ & $30.83(28.40)$ & $19.28(15.07)$ & $21.57(16.01)$ & $<0.0001^{\mathrm{a}}$ \\
\hline \multicolumn{6}{|l|}{ Obstetric history (mean (SD)) } \\
\hline Pregnancies & $0.36(0.79)$ & $0.36(0.79)$ & $0.52(0.87)$ & $0.32(0.75)$ & $<0.0001^{a}$ \\
\hline Deliveries & $0.26(0.60)$ & $0.26(0.60)$ & $0.37(0.71)$ & $0.22(0.56)$ & $<0.0001^{a}$ \\
\hline Abortions (spontaneous) & $0.05(0.26)$ & $0.05(0.25)$ & $0.09(0.35)$ & $0.05(0.23)$ & $0.001^{\mathrm{a}}$ \\
\hline Abortions (induced) & $0.08(0.35)$ & $0.09(0.38)$ & $0.12(0.38)$ & $0.06(0.27)$ & $<0.0001^{\mathrm{a}}$ \\
\hline Live childbirths & $0.17(0.50)$ & $0.17(0.50)$ & $0.22(0.58)$ & $0.14(0.47)$ & $0.0004^{\mathrm{a}}$ \\
\hline \multicolumn{6}{|l|}{ Stable partner } \\
\hline Yes & 7,106 (82.1\%) & 4,367 (81.5\%) & $679(80.6 \%)$ & 2,060 (83.9\%) & $<0.0153^{b}$ \\
\hline No & $1,549(17.9 \%)$ & 991 (18.5\%) & $164(19.5 \%)$ & $394(16.1 \%)$ & \\
\hline Education & & & & & $<0.0001^{\mathrm{b}}$ \\
\hline Primary & $934(10.8 \%)$ & 655 (12.2\%) & 109 (12.9\%) & $170(6.9 \%)$ & \\
\hline Secondary & $3,885(44.8 \%)$ & $2,479(46.2 \%)$ & 406 (47.9\%) & $1,000(40.5 \%)$ & \\
\hline University & $3,863(44.5 \%)$ & $2,233(41.6 \%)$ & 333 (39.3\%) & $1,297(52.6 \%)$ & \\
\hline Occupational status & & & & & $<0.0001^{\mathrm{b}}$ \\
\hline Working outside the home & $4,960(57.3 \%)$ & $3,018(56.28 \%)$ & $476(56.4 \%)$ & $1,466(59.6 \%)$ & \\
\hline Homemaker & $561(6.5 \%)$ & $363(6.8 \%)$ & $90(10.7 \%)$ & $108(4.4 \%)$ & \\
\hline Student & 2,353 (27.2\%) & $1,451(27.1 \%)$ & $208(24.6 \%)$ & $694(28.2 \%)$ & \\
\hline Unemployed & $790(9.1 \%)$ & $530(9.9 \%)$ & $70(8.3 \%)$ & $190(7.7 \%)$ & \\
\hline \multicolumn{6}{|l|}{ Reasons for omission/delay } \\
\hline Forgetfulness/delays & $2,622(71.2 \%)$ & 1,996 (74.9\%) & $172(47.8 \%)$ & $494(69.1 \%)$ & $<0.0001^{\mathrm{b}}$ \\
\hline Altered libido & $214(5.8 \%)$ & $180(6.8 \%)$ & $14(3.9 \%)$ & $20(3.0 \%)$ & $0.0003^{b}$ \\
\hline Weight gain & $211(5.7 \%)$ & $201(7.5 \%)$ & $4(1.1 \%)$ & $6(0.9 \%)$ & $<0.0001^{\mathrm{b}}$ \\
\hline \multicolumn{6}{|l|}{ Common course of action after noncompliance } \\
\hline Use the contraceptive as soon as possible & $2,396(65.1 \%)$ & $1,745(65.5 \%)$ & $235(65.3 \%)$ & $416(63.3 \%)$ & $0.5868^{b}$ \\
\hline Consult a health care provider & $598(22.1 \%)$ & $337(16.2 \%)$ & $76(14.1 \%)$ & $145(21.1 \%)$ & $<0.0001^{\mathrm{b}}$ \\
\hline Use two or more methods to compensate for the days missed & $353(9.6 \%)$ & $339(12.7 \%)$ & $5(1.4 \%)$ & $9(1.4 \%)$ & $<0.0001^{\mathrm{b}}$ \\
\hline Routine method & & & & & $<0.0001^{\mathrm{b}}$ \\
\hline At the same time every day & $5,837(67.6 \%)$ & $3,621(67.6)$ & $515(61.0 \%)$ & $1,701(70.0 \%)$ & \\
\hline Daily task & $1,472(17.1 \%)$ & $933(17.4)$ & $168(19.9 \%)$ & $371(15.3 \%)$ & \\
\hline Thinking of it but not yet organized & $712(8.3 \%)$ & $514(9.6 \%)$ & $85(10.1 \%)$ & $113(4.7 \%)$ & \\
\hline Not interested & $183(2.1 \%)$ & $117(2.2 \%)$ & $38(4.5 \%)$ & $28(1.2 \%)$ & \\
\hline Others & $429(5.0 \%)$ & $174(3.3 \%)$ & $38(4.5 \%)$ & $217(8.9 \%)$ & \\
\hline \multicolumn{6}{|l|}{ Difficulties remembering to use the contraceptive method } \\
\hline During the week, from Monday to Friday & $856(9.8 \%)$ & $510(9.4 \%)$ & $86(10.1 \%)$ & $260(10.5 \%)$ & $0.3234^{b}$ \\
\hline On vacation & $2,745(31.3 \%)$ & $1,531(28.2 \%)$ & $279(32.6 \%)$ & $935(37.6 \%)$ & $<0.0001^{\mathrm{b}}$ \\
\hline On weekend & $2,426(27.7 \%)$ & $1,889(34.8 \%)$ & $175(20.4 \%)$ & $362(14.6 \%)$ & $<0.0001^{\mathrm{b}}$ \\
\hline On short trips & $966(11.0 \%)$ & $606(11.2 \%)$ & $101(11.8 \%)$ & $259(10.4 \%)$ & $0.4592^{b}$ \\
\hline Going out the night before & $1,127(12.9 \%)$ & $863(15.9 \%)$ & $114(13.3 \%)$ & $150(6.0 \%)$ & $<0.0001^{\mathrm{b}}$ \\
\hline Travelling to a different time zone & $513(5.9 \%)$ & $206(3.8 \%)$ & 46 (5.4\%) & 261 (10.5\%) & $<0.0001^{\mathrm{b}}$ \\
\hline
\end{tabular}

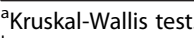

${ }^{\mathrm{b}}$ Chi-squared test.

$\mathrm{p}<0.05$.

SD: Standard Deviation. 


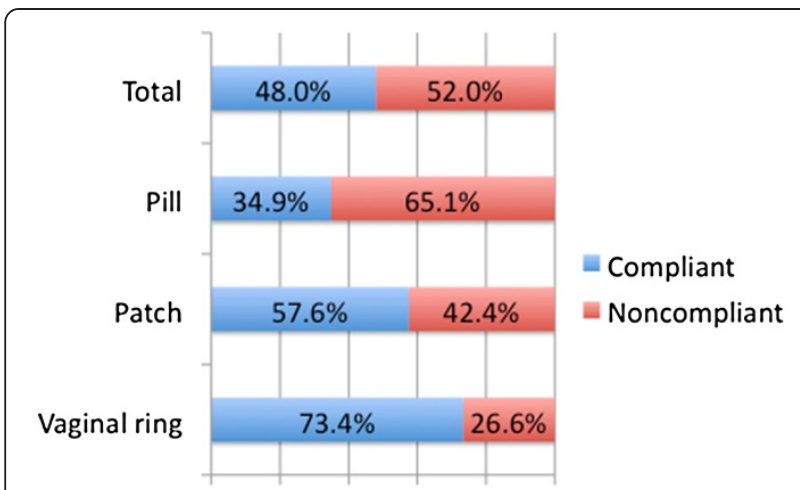

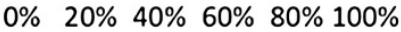

Figure 1 Compliance/noncompliance according to the contraceptive method used.

vaginal ring users $(\mathrm{p}<0.0001)$. Almost $12.7 \%$ of the women taking the pill used two or more methods to compensate for the days missed compared with $1.4 \%$ for women using the vaginal ring $(\mathrm{p}<0.0001)$. The next most common decision was to do nothing, more often between pill users $(\mathrm{p}<0.0001)$.

The compliance comparison showed that the amount of time using the current method (months) was higher in noncompliant women than in compliant ones(24.8 compliant women vs 29,1 noncompliant women; $\mathrm{p}<$ 0.0001 ), and that the degree of information and degree of understanding the information and instructions of the used method were lower in noncompliant women compared to compliant women. More than half of the women $(51.1 \%)$ believe that if they could participate in the choice of the contraceptive method they would have less forgetfulness/delays, mainly noncompliant women compared with compliant women $(57.0 \%$ vs $44.1 \%$, $\mathrm{p}<0.0001)$. The partner support and interest in not becoming pregnant were also lower in noncompliant women. Not having a routine or having difficulties remembering to use the contraceptive method involves higher noncompliance (Table 2).

A multiple logistic regression analysis (stepwise method) was performed to determinate which factors might affect the probability of noncompliance of a user (Table 3). The analysis revealed that the length of time using the contraceptive method was likely to play a role in the noncompliance therapy [OR $(95 \% \mathrm{CI}): 1.006$ (1.004-1.008), $\mathrm{p}<0.0001]$. Depending on the contraceptive method the level of noncompliance can be higher $(\mathrm{p}<0.0001)$ : using pill increased the probability of noncompliance compared with the patch [OR ( $95 \% \mathrm{CI}): 2.53$ (2.13-3.02)] and compared with the vaginal ring [OR (95\% CI) 4.18 (3.68-4.73)], and the use of patch increased the probability of noncompliance [OR $(95 \% \mathrm{CI}): 1.65$
(1.36-1.99)] compared with the vaginal ring. Low level of user's information treatment and a poor understanding of information and instructions were also associated with a higher probability of noncompliance. Compared with women interested not becoming pregnant, the probabilities of noncompliance increased for women preferring to not get pregnant [OR (95\%): 1.27 (1.061.53)] and women who would not mind [OR (95\%): 1.46 (1.00-2.12)]. Having a partner indifferent to a possible pregnancy or the absence of a partner also increased the probability of noncompliance. Moreover, the lack of support from one's partner or the absence of a partner was also a factor that may affect the noncompliance increased. The probability of noncompliance was higher in women who think that if they could participate in the decision to choose the contraceptive method would have fewer delays/omissions, that it, they would be more compliant.

The use of a method to remember the medication was another factor associated with the noncompliance. Not being interested in a routine method, having considered it but not being organized yet and doing an activity that provided a reminder on treatment increased the noncompliance compared always taking or applying the medication always at the same hour.

Finally, the noncompliance increased in women with difficulties remembering to take/use/remove the contraceptive method: during the week (Monday-Friday), on weekends, on vacation, on short trips, after going out the night before and when travelling to a different time zone).

A recommendation for switching was made regardless of the current method (43.2\%), although this recommendation was made to a lower percentage of women using the vaginal ring than to the other groups (pill, 51.8\%; patch, 58.2\%; vaginal ring, $19.4 \%$ ). The reasons given by the gynecologist for switching method varied according to the current method and the degree of compliance. Patients were advised to switch to the pill for reasons of tolerance. In the case of the patch or vaginal ring, the switch was recommended for reasons of convenience in compliers and for reasons of compliance in noncompliers.

\section{Discussion}

The study analyzed 3 widely used contraceptive methods in a sample that was sufficiently large to enable to present the results with a significant degree of precision (the precision reached with the final sample was $1 \%$. It is not significantly difference from the initially proposed sample $-0.9 \%-)$. Most of the women in the study used the pill (61.9\%), a finding that is consistent with the 
Table 2 Profile of the study population according to compliance

\begin{tabular}{|c|c|c|c|c|}
\hline & Total & Compliant & Noncompliant & p Value \\
\hline Age, years (mean (SD)) & $25.29(4.79)$ & $25.50(4.77)$ & $25.10(4.79)$ & $<0.0001^{a}$ \\
\hline Time using the current method, months (mean (SD)) & $27.08(24.84)$ & $24.82(23.28)$ & $29.16(26.04)$ & $<0.0001^{\mathrm{a}}$ \\
\hline \multicolumn{5}{|l|}{ Obstetric history (mean (SD)) } \\
\hline Pregnancies & $0.36(0.79)$ & $0.35(0.74)$ & $0.38(0.83)$ & $<0.3966^{a}$ \\
\hline Deliveries & $0.26(0.60)$ & $0.25(0.57)$ & $0.27(0.63)$ & $<0.5212^{a}$ \\
\hline Abortions (spontaneous) & $0.05(0.26)$ & $0.05(0.26)$ & $0.05(0.26)$ & $<0.7648^{\mathrm{a}}$ \\
\hline Abortions (induced) & $0.08(0.35)$ & $0.06(0.27)$ & $0.10(0.42)$ & $<0.0001^{\mathrm{a}}$ \\
\hline Live childbirths & $0.17(0.50)$ & $0.15(0.47)$ & $0.18(0.53)$ & $0.0436^{\mathrm{a}}$ \\
\hline Stable partner & & & & $<0.0001^{b}$ \\
\hline Yes & $7,106(82.1 \%)$ & $3,525(84.9 \%)$ & 3,581 (79.5\%) & \\
\hline No & 1,549 (17.9\%) & $628(15.1 \%)$ & $921(20.5 \%)$ & \\
\hline Education & & & & $<0.0001^{\mathrm{c}}$ \\
\hline Primary & $934(10.8 \%)$ & $358(8.6 \%)$ & $576(12.8 \%)$ & \\
\hline Secondary & $3,885(44.8 \%)$ & $1,817(43.6 \%)$ & $2,068(45.8 \%)$ & \\
\hline University & $3,863(44.5 \%)$ & 1,993 (47.8\%) & $1,870(41.4 \%)$ & \\
\hline Occupational status & & & & $<0.0003^{c}$ \\
\hline Working outside the home & $4,960(57.3 \%)$ & 2,474 (59.5\%) & 2,486 (55.2\%) & \\
\hline Homemaker & $561(6.5 \%)$ & $244(5.9 \%)$ & $317(7.0 \%)$ & \\
\hline Student & 2,353 (27.2\%) & 1,091 (26.2\%) & 1,262 (28.0\%) & \\
\hline Unemployed & $790(9.1 \%)$ & $349(8.4 \%)$ & $441(9.8 \%)$ & \\
\hline Information on treatment & & & & $<0.0001^{c}$ \\
\hline Very informed & $902(44.8 \%)$ & $2,309(55.2 \%)$ & 1,593 (35.1\%) & \\
\hline Normal & $4,495(51.5 \%)$ & $1,814(43.4 \%)$ & 2,681 (59.2\%) & \\
\hline Not very informed & 307 (3.5\%) & $61(1.4 \%)$ & $246(5.4 \%)$ & \\
\hline Not interested & $15(0.2 \%)$ & $0(0 \%)$ & $15(0.3 \%)$ & \\
\hline Understanding of information and instructions & & & & $<00001^{c}$ \\
\hline Not interested & $11(0.1 \%)$ & $2(0.05 \%)$ & $9(0.2 \%)$ & \\
\hline Anything & $20(0.2 \%)$ & $4(0.1 \%)$ & $16(0.4 \%)$ & \\
\hline Not understanding a lot of things & $393(4.5 \%)$ & $70(1.7 \%)$ & $323(7.1 \%)$ & \\
\hline Understanding almost all & $2,719(31.2 \%)$ & $1,046(24.9 \%)$ & $1,673(36.9 \%)$ & \\
\hline Complete understanding & $5,587(64.1 \%)$ & $3,076(73.3 \%)$ & $2,511(55.4 \%)$ & \\
\hline Partner support & & & & $<.0001^{\mathrm{c}}$ \\
\hline Always reminding & 2,992 (34.3\%) & $1,724(41.2 \%)$ & $1,268(28.1 \%)$ & \\
\hline Absence of partner & $1,128(13.0 \%)$ & $458(10.9 \%)$ & $670(14.8 \%)$ & \\
\hline Indifferent & $1,349(15.5 \%)$ & $540(12.9 \%)$ & $809(17.9 \%)$ & \\
\hline Sometimes & $3,239(37.2 \%)$ & $1,467(35.0 \%$ & $1,772(39.2 \%)$ & \\
\hline Interest in not becoming pregnant & & & & $<.0001^{\mathrm{c}}$ \\
\hline Very interested & $5,823(66.7 \%)$ & 2,893 (68.9\%) & $2,930(64.6 \%)$ & \\
\hline Interested & $1,551(17.8 \%)$ & 737 (17.6\%) & $814(18.0 \%)$ & \\
\hline Prefer not to get pregnant & $1,174(13.5 \%)$ & $489(11.7 \%)$ & $685(15.1 \%)$ & \\
\hline Not mind & 179 (2.0\%) & $76(1.8 \%)$ & $103(2.3 \%)$ & \\
\hline
\end{tabular}


Table 2 Profile of the study population according to compliance (Continued)

\begin{tabular}{|c|c|c|c|c|}
\hline \multicolumn{4}{|l|}{ Belief that participation would avoid forgetfulness/delays } & \multirow[t]{4}{*}{$<0.0001^{c}$} \\
\hline More & $564(6.6 \%)$ & $349(8.6 \%)$ & 215 (4.8\%) & \\
\hline The same & $3,613(42.3 \%)$ & $1,905(46.9 \%)$ & $1,708(38.2 \%)$ & \\
\hline Less & 4,357 (51.1\%) & $1,808(44.5 \%)$ & $2,549(57.0 \%)$ & \\
\hline \multicolumn{5}{|l|}{ Routine method } \\
\hline At the same time every day & $5,837(67.6 \%)$ & $2,990(72.1 \%)$ & $2,847(63.5 \%)$ & \multirow[t]{5}{*}{$<0.0001^{\mathrm{c}}$} \\
\hline Daily task & $1,472(17.1 \%)$ & $746(18.0 \%)$ & $726(16.2 \%)$ & \\
\hline Thinking of it but not yet organized & 712 (8.3\%) & $96(2.3 \%)$ & 616 (13.7\%) & \\
\hline Not interested & $183(2.1 \%)$ & $60(1.5 \%)$ & $123(2.7 \%)$ & \\
\hline Other & $429(4.3 \%)$ & $254(6.1 \%)$ & $175(3.9 \%)$ & \\
\hline \multicolumn{5}{|c|}{ Difficulties remembering to take/use/remove the contraceptive method } \\
\hline During the week, from Monday to Friday & $856(9.8 \%)$ & $221(5.3 \%)$ & $635(14.0 \%)$ & $<0.0001^{\mathrm{b}}$ \\
\hline On vacation & $2,745(31.3 \%)$ & $1,372(32.6 \%)$ & $1,373(30.2 \%)$ & $0.015^{b}$ \\
\hline On weekend & $2,426(27.7 \%)$ & $756(18.0 \%)$ & $1,670(36.7 \%)$ & $<0.0001^{\mathrm{b}}$ \\
\hline On short trips & $966(11.0 \%)$ & $492(11.7 \%)$ & $474(10.4 \%)$ & $0.0604^{b}$ \\
\hline Going out the night before & 1127 (12.9\%) & $422(10.0 \%)$ & $705(15.5 \%)$ & $<0.0001^{\mathrm{b}}$ \\
\hline Travelling to a different time zone & $513(5.9 \%)$ & $328(7.8 \%)$ & 185 (4.1\%) & $<0.0001^{\mathrm{b}}$ \\
\hline
\end{tabular}

ailcoxon-Mann-Whitney test.

${ }^{b}$ Fisher exact test.

${ }^{\mathrm{c} C h i}$-squared test.

$\mathrm{p}<0.05$.

SD: Standard Deviation.

results of a survey of contraceptive use among women from 5 European countries [1].

Compliance varies according to the delivery method chosen. That the study showed that more than half (52.0\%) of the women do not apply their contraceptive method according to the instructions in the package insert, especially in pill users. The main reason for missing/delays in using the contraceptive method in the study was simple forgetfulness, although some women complained of side effects such as altered libido or weight gain. A large noncompliance rate and women's difficulties in maintaining safe contraception after missing a pill were observed in others studies [16,17]. Westhoff et al. [18] found that most women discontinued for reasons not associated with side effects. One study showed that compliance was greater with the vaginal ring than with the pill [19], whereas others show consistent perfect compliance with the transdermal patch $[20,21]$.

Not having a regular routine has been shown to be one of the strongest risk factors for poor compliance. Women who do not have a regular routine for pill taking are more than 3 times more likely to be inconsistent users [6]. Memory aids such as associating pill taking with another daily action or leaving the pill package visible, have also been associated with easier compliance [22].

The study shows that not having a stable partner increased noncompliance. Whenever both members of a couple are convinced that they do not want a pregnancy, the participation of the partner has been shown to be effective in increasing adherence [23]. This study, in agreement with other studies, also demonstrated that the low level of information on the contraceptive treatment and poor understanding of information and instruction influence noncompliance [24].

Indeed, several authors have shown that the quality of family planning counseling could affect continuation with a particular method [25]. Halpern et al. [7] suggested that, while enhanced counseling has a limited effect on continuation, it could change the reasons why women discontinue contraception. Furthermore, Grove and Hooper [26] stress the need for physicians to make recommendations that are tailored to a woman's medical profile and preferences.

The relationship with the health care provider is paramount in ensuring compliance, and one study of adolescent women showed that if the physician was considered to be helpful, then users were more compliant [27].

In addition, the physician must be able to provide an alternative method, should compliance prove difficult with the initially chosen one [28]. In this study, a recommendation for switching was made by the clinician after analyzing the reasons for noncompliance of the users, although this recommendation was made to a lower percentage of women using the vaginal ring than to the other groups (pill, 51.8\%; patch, 58.2\%; vaginal ring, $19.4 \%)$. 
Table 3 Multiple logistic regression analysis

\begin{tabular}{|c|c|c|c|c|}
\hline \multirow{2}{*}{\multicolumn{2}{|c|}{$\begin{array}{l}\text { Factor } \\
\text { Time using the current method, months (continuous variable) }\end{array}$}} & \multirow{2}{*}{$\frac{\text { OR estimate }}{1.006}$} & \multirow{2}{*}{$\begin{array}{l}\text { OR } 95 \% \mathrm{Cl} \\
1.004-1.008\end{array}$} & \multirow{2}{*}{$\begin{array}{l}\text { p-value } \\
<0.0001\end{array}$} \\
\hline & & & & \\
\hline \multirow[t]{3}{*}{ Contraceptive method } & Pill vs vaginal ring & 4.175 & $3.683-4.732$ & $<0.0001$ \\
\hline & Patch vs vaginal ring & 1.648 & $1.362-1.994$ & \\
\hline & Pill vs Patch & 2.534 & $2.128-3.016$ & \\
\hline Information on treatment & Not very informed & 1.931 & $1.336-2.791$ & $<0.0001$ \\
\hline (reference: very informed) & Normal & 1.532 & $1.370-1.713$ & \\
\hline Interest in not becoming pregnant & Very interested & 1.161 & $1.012-1.332$ & $<0.0001$ \\
\hline \multirow[t]{2}{*}{ (reference: interested) } & Prefer not to get pregnant & 1.273 & $1.057-1.534$ & \\
\hline & Not mind & 1.455 & $1.001-2.117$ & \\
\hline Partner support & Absence of partner & 1.415 & $1.195-1.676$ & $<0.0001$ \\
\hline \multirow[t]{2}{*}{ (reference: always reminding) } & Indifferent & 1.416 & $1.205-1.664$ & \\
\hline & Sometimes & 1.372 & $1.214-1.550$ & \\
\hline Understanding of information and instructions & Not interested & 2.137 & $0.182-25.052$ & 0.0089 \\
\hline \multirow[t]{3}{*}{ (reference: complete understanding) } & Anything & 1.066 & $0.283-4.014$ & \\
\hline & Not understanding a lot of things & 1.696 & $1.213-2.371$ & \\
\hline & Understanding almost all & 1.167 & $1.032-1.318$ & \\
\hline \multirow[t]{3}{*}{ Belief that participation would avoid forgetfulness/delays } & More vs The same & 1.072 & $0.865-1.329$ & $<0.0001$ \\
\hline & Less vs The same & 1.298 & $1.167-1.444$ & \\
\hline & Less vs More & 1.211 & $0.977-1.501$ & \\
\hline Routine method & Other & 1.142 & $0.902-1.447$ & $<0.0001$ \\
\hline \multirow[t]{3}{*}{ (reference: at the same hour each day of the week/month) } & Not interested & 1.470 & $1.003-2.154$ & \\
\hline & Considered but not organized & 3.873 & $2.997-5.004$ & \\
\hline & Activity reminding treatment & 0.846 & $0.740-0.968$ & \\
\hline $\begin{array}{l}\text { Difficulties remembering to take/use/remove the } \\
\text { contraceptive method }\end{array}$ & $\begin{array}{l}\text { During the week, from Monday } \\
\text { to Friday }\end{array}$ & 6.189 & $4.982-7.687$ & $<0.0001$ \\
\hline \multirow[t]{5}{*}{ (reference: none) } & On vacation & 2.132 & $1.851-2.455$ & $<0.0001$ \\
\hline & On weekend & 3.392 & $2.934-3.921$ & $<0.0001$ \\
\hline & On short trips & 1.563 & $1.306-1.871$ & $<0.0001$ \\
\hline & Going out the night before & 2.099 & $1.762-2.501$ & $<0.0001$ \\
\hline & Travelling to a different time zone & 1.403 & $1.106-1.780$ & $<0.0001$ \\
\hline
\end{tabular}

Goodness-of-fit (Hosmer-Lemeshow): $\mathrm{p}$-value $=0.7004$.

Discrimination test: $\mathrm{p}$-value $=0.7830$.

Abbreviations: $\mathrm{Cl}$ Confidence Interval.

Probability modeled is noncompliance (code $=1$ ).

This study draws the attention to the gynecologist about the factors associated with noncompliance to the contraceptive method (pill, patch, vaginal ring), so the health professional can recommend a change of treatment that best suits the user profile.

Nevertheless, the study is subject to a series of limitations. First its cross-sectional design means that it is not possible to describe those factors that affect compliance; making unable to predict outcomes or draw conclusions about causal relationships. Second, as the study population comprises young women who may have little experience of using combined hormonal contraceptives, our findings cannot be extrapolated to other age groups.
Third, a more accurate definition of compliance would enable us to rule out any potential bias in the comparison of the 3 methods. Fourth, the used method of assessing compliance was indirect, namely, by selfadministered questionnaire; therefore the resulting data are not as objective as those obtained using more direct methods.

\section{Conclusions}

The findings from this study conclude that more than half of the women were noncompliant, but the frequency of their noncompliance varied with the method used. Other factors associated to increase the noncompliance were: high 
treatment duration, low level information treatment, poor understanding of information and instructions, not interest becoming pregnant, low partner's support or absence of partner, non-participation in the choice of contraceptive method, low level of interest in a routine method or difficulties remembering to take/use the contraceptive method. Understanding the user's reasons for noncompliance by the clinician and encouraging a collaborative approach can go a long way to improving compliance.

\section{Additional file}

Additional file 1: Investigators of the MIA study.

\section{Abbreviations}

Cl: Confidence interval; OR: Odds ratio; SD: Standard deviation.

\section{Competing interest}

The authors declare that they have no competing interests.

\section{Authors' contributions}

TMAOZ participated in study design, data analysis and interpretation, and drafting and writing the manuscript. TDM and TMAC participated in its design and coordination and helped to draft the manuscript. All authors read and approved the final manuscript.

\section{Acknowledgments}

The study was sponsored by the Spanish Society of Gynecology and Obstetrics (Sociedad Española de Ginecología y Obstetricia [SEGO]), and was funded by a research grant from Merck, Sharp \& Dohme, Spain. We thank all the participating investigators for their contribution to the study.

An additional file shows the list of investigators in more detail [see Additional file 1]

Received: 29 November 2012 Accepted: 9 October 2013 Published: 20 October 2013

\section{References}

1. Skouby SO: Contraceptive use and behavior in the 21st century: a comprehensive study across five European countries. Eur J Contracept Reprod Health Care 2004, 9:57-68.

2. Lete I, Bermejo R, Coll C, Dueñas JL, Doval JL, Martinez-Salmeán J, Parrilla JJ, Serrano I: Spanish population at risk of unwanted pregnancy: results of a national survey. Eur J Contracept Reprod Health Care 2003, 8:75-79.

3. Darney PD: A hormonal contraception update 2010: a decade of innovation \& transformation. Am J Obstet Gynecol 2011, 205:S1-S24.

4. Rosenberg MJ, Waugh MS, Long S: Unintended pregnancies and use, misuse and discontinuation of oral contraceptives. J Reprod Med 1995, 40:355-360.

5. Rosenberg M, Waugh MS: Causes and consequences of oral contraceptive noncompliance. Am J Obstet Gynecol 1999, 180:S276-S279.

6. Rosenberg MJ, Waugh M, Meehan T: Use and misuse of oral contraceptives: risk indicators for poor pill taking and discontinuation. Contraception 1995, 51:283-288.

7. Halpern V, Lopez LM, Grimes DA, Gallo MF: Strategies to improve adherence and acceptability of hormonal methods of contraception. Cochrane Database Syst Rev 2011, 4, CD004317.

8. Lopez LM, Grimes DA, Gallo MF, Schulz KF: Skin patch and vaginal ring versus combined oral contraceptives for contraception. Cochrane Database Syst Rev 2008, 1, CD003552

9. Bitzer J, Simon JA: Current issues and available options in combined hormonal contraception. Contraception 2011, 84:342-356.

10. Egarter C, Frey TB, Bitzer J, Kaminskyy V, Oddens BJ, Prilepskaya V, Yeshaya A, Marintcheva-Petrova M, Weyers S: Women's Perceptions and reasons for choosing the pill, patch, or ring in the CHOICE study: a cross-sectional survey of contraceptive method selection after counseling. BMC Womens Health 2013, 13:9.
11. Lete I, Doval JL, Pérez-Campos E, Letxundi R, Correa M, de la Viuda E, Gómez MA, González JV, Martínez MT, Mendoza N, Robledo J: Selfdescribed impact of noncompliance among users of a combined hormonal contraceptive method. Contraception 2008, 77:276-282.

12. Lete I, Doval JL, Pérez-Campos E, Sánchez-Borrego R, Correa M, de la Viuda E, Gómez MA, González JV, Lertxundi R, Martínez MT, Mendoza N, Robledo $\mathrm{J}$ : Factors affecting women's selection of a combined hormonal contraceptive method: the TEAM-06 Spanish cross-sectional study. Contraception 2007, 76:77-83.

13. Oddson K, Leifels-Fischer B, de Melo NR, Wiel-Masson D, Benedetto C, Verhoeven $\mathrm{CH}$, Dieben TO: Efficacy and safety of a contraceptive vaginal ring (NuvaRing) compared with a combined oral contraceptive: a 1-year randomized trial. Contraception 2005, 71:176-182.

14. Roumen FJ: Review of the combined contraceptive vaginal ring, NuvaRing. Ther Clin Risk Manag 2008, 4:441-451.

15. Jakimiuk AJ, Crosignani PG, Chernev T, Prilepskaya V, Bergmans $P$, Von Poncet M, Marelli S, Lee EJ: High levels of women's satisfaction and compliance with transdermal contraception: results from a European multinational, 6-month study. Gynecol Endocrinol 2011, 27:849-856.

16. Potter L, Oakley D, de Leon-Wong E, Cañamar R: Measuring compliance among oral contraceptive users. Fam Plann Perspect 1996, 28(4):154-158.

17. Aubeny E, Buhler M, Colau JC, Vicaut E, Zadikian M, Childs M, The Coraliance study: non-compliant behavior: Results after a 6-month follow-up of patients on oral contraceptives. Eur J Contracept Reprod Health Care 2004 9(4):267-277.

18. Kalmuss D, Cushman L, Robilotto T, Davis A, Cwiak C, Stuart G, Zieman M, Edwards S, Heartwell S, Westhoff CL: Oral contraceptive discontinuation: do side effects matter? Am J Obstet Gynecol 2007, 196:6-7.

19. Aubeny E, Buhler M, Colau JC, Vicaut E, Zadikian M, Childs M: Oral contraception: patterns of non-compliance. The Coraliance study. Eur J Contracept Reprod Health Care 2002, 7:155-161.

20. Weisberg F, Bouchard C, Moreau M, Audet MC, Mawdsley S, Dattani D, Dinniwell J, Horbay GL, NRGEEP-CON-401 Study Group: Preference for and satisfaction of Canadian women with the Transdermal contraceptive patch versus previous contraceptive method: an open label, multicentre study. J Obstet Gynaecol Can 2005, 27:350-359.

21. Archer DF, Bigrigg A, Smallwood GH, Shangold GA, Creasy GW, Fisher AC: Assessment of compliance with a weekly contraceptive patch (Ortho Evra/Evra) among North American women. Fertil Steril 2002, 77:S27-S31.

22. Milsom I, Lete I, Bjertnaes A, Rokstad K, Lindh I, Gruber CJ, Birkhäuser MH, Aubeny $E$, Knudsen T, Bastianelli C: Effects on cycle control and bodyweight of the combined contraceptive ring, NuvaRing, versus an oral contraceptive containing 30 microg ethinyl estradiol and $3 \mathrm{mg}$ drospirenone. Hum Reprod 2006, 21:2304-2311.

23. Lara-Torre E, Spotswood L, Correia N, Weiss PM: Intrauterine contraception in adolescents and young women: a descriptive study of use, side effects, and compliance. J Pediatr Adolesc Gynecol 2011, 24:39-41.

24. Halpern V, Lopez LM, Grimes DA, Gallo MF: Strategies to improve adherence and acceptability of hormonal methods of contraception. Cochrane Database Syst Rev 2011, 13, CD004317.

25. Blanc AK, Curtis SL, Croft TN: Monitoring contraceptive continuation: links to fertility outcomes and quality of care. Stud Fam Plann 2002, 33:127-140.

26. Grove D, Hooper DJ: Doctor contraceptive-prescribing behaviour and women's attitudes towards contraception: two European surveys. J Eval Clin Pract 2011, 17:493-502.

27. Durant RH, Jay MS, Linder CW, Shofitt T, Litt I: Influence of psychosocial factors on adolescent compliance with oral contraceptives. J Adolesc Health Care 1984, 5:1-6.

28. Rosenberg MJ, Waugh MS: Oral contraceptive discontinuation: a prospective evaluation of frequency and reasons. Am J Obstet Gynecol 1998, 179:577-582.

\section{doi:10.1186/1472-6874-13-38}

Cite this article as: Martínez-Astorquiza-Ortiz de Zarate et al.: Evaluation of factors associated with noncompliance in users of combined hormonal contraceptive methods: a cross-sectional study: results from the MIA study. BMC Women's Health 2013 13:38. 